\title{
Implantosuported Rehabilitation after Marginal Recession of Mandibular Calcifying Epithelial Odontogenic Tumor: Case Report
}

\author{
Bruna Barcelos Ferreira, Victor Tieghi Neto, Andréa Guedes Barreto Gonçales, \\ Denise Tostes Oliveira, Fábio Sanches Magalhães Tunes, Eduardo Sanches Gonçales* \\ Department of Surgery, Stomatology, Pathology and Radiology of the Sao Paulo University, Bauru School of Dentistry, \\ Bauru, Brazil \\ Email: *eduardogoncales@usp.br
}

How to cite this paper: Ferreira, B.B., Neto, V.T., Gonçales, A.G.B., Oliveira, D.T., Tunes, F.S.M. and Gonçales, E.S. (2019) Implantosuported Rehabilitation after Marginal Recession of Mandibular Calcifying Epithelial Odontogenic Tumor: Case Report. Open Journal of Stomatology, 9, 199-207.

https://doi.org/10.4236/ojst.2019.99021

Received: July 26, 2019

Accepted: September 3, 2019

Published: September 6, 2019

Copyright $\odot 2019$ by author(s) and Scientific Research Publishing Inc. This work is licensed under the Creative Commons Attribution International License (CC BY 4.0).

http://creativecommons.org/licenses/by/4.0/

\begin{abstract}
The Calcifying Epithelial Odontogenic Tumor (CEOT) also called the Pindborg's Tumor represents a rare benign epithelial odontogenic neoplasm with locally aggressive behavior. Surgical excision with a safety margin is one of the treatment options, requiring bone and soft tissue reconstruction for implant-supported rehabilitation, providing the individual with a return to adequate oral functions. The objective of the present study is to report on the case of the treatment stages and the factors involved in the rehabilitation of a 23-year-old man with a history of mandibular lesion diagnosed as CEOT. A marginal resection of the mandible lesion was performed, with posterior reconstruction with iliac crest bone graft and soft tissue graft to allow the implant-supported rehabilitation. Currently, in the postoperative control, the individual shows no signs of tumor recurrence and is rehabilitated without functional and/or aesthetic complaints. Surgical excision should be framed as a form of treatment, aiming for better resolution in the more complex cases of these invasive tumors.
\end{abstract}

\section{Keywords}

Oral Pathology, Bone Reconstruction, Dental Implants, Oral Rehabilitation

\section{Introduction}

The Calcifying Epithelial Odontogenic Tumor (CEOT) was first described by Pindborg in 1955. It is an uncommon Odontogenic lesion and occurs less than $1 \%$ of all odontogenic tumors [1] [2]. It is locally aggressive and the surgical ex- 
cision with safety margin is the best treatment option. Procedures for treatment that involve enucleation and curettage are also an option, but high rates of tumor recurrence are associated with then [3] [4]. Enucleation is the treatment of choice, removing the tumor and adjacent bone, teeth and soft tissue, making necessary reconstructive procedures for rehabilitation.

In general, in addition to the size and anatomical location of the tumor, factors such as patient's medical condition, patient's tolerance to the procedure, surgeon's skills and experience and histopathological characteristics should be considered in order to establish better treatment plan [3] [4] [5].

When the option of surgical excision is made, the main purpose of bone reconstruction is restoring the anatomical features, masticatory function and aesthetic at the end of the treatment. In addition, implant-supported rehabilitation should be planned, providing the patient suitable masticatory function and aesthetics [6] [7] [8] [9].

In order to perform osseous reconstructions after mandibular resection, different approaches are described, either in relation to the kind of reconstruction or the best time to do so and also different treatment protocols for prosthetic rehabilitation, which in many cases involve reconstructive surgeries of soft tissue [7].

The objective is to report a case diagnosed as CEOT, demonstrating the stages of treatment from diagnosis to implant-supported rehabilitation and the factors involved in rehabilitation after marginal resection of the tumor.

\section{Case Report}

Male, 23 years old, had a history of mandibular lesion showing swelling with reddish spots in some areas and whitish in others, resilient consistency and smooth texture, asymptomatic, involving vestibular and lingual ridge and anterior mandibular teeth, approximately $4.0 \mathrm{~cm}$ in diameter (Figure 1(a)). Teeth 31 and 41 presented mobility and teeth 32,33 and 42 without pulp vitality when evaluated. Radiographic examination revealed a radiolucent image with irregular borders extending from the dental elements 32 to 43 , teeth 31 and 41 with channel treated (Figure 1(b)).

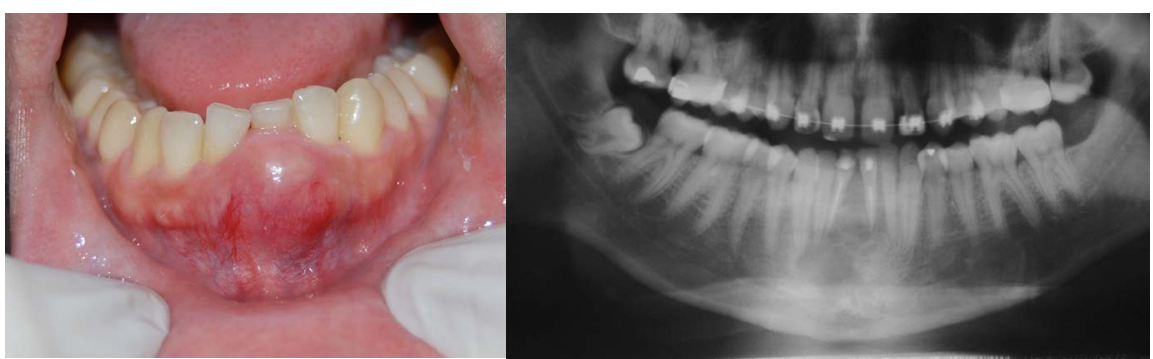

(a)

(b)

Figure 1. (a) Initial clinical aspect of the lesion. Swelling with reddish spots in some areas and whitish in others, resilient consistency and smooth texture with approximately 3.5 $\mathrm{cm}$ in diameter in the anterior region of mandible; (b) Initial panoramic radiograph. Multilocular radiolucent image of the irregular border region of mandibular symphysis. 


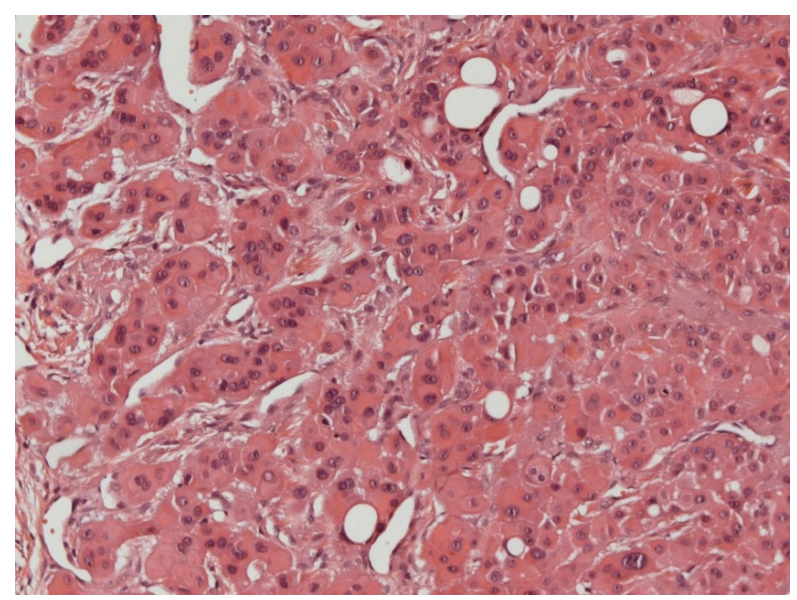

Figure 2. Histological section demonstrating the presence of cords of polyhedral epithelial cells with eosinophilic cytoplasm, intercellular bridges, few mitotic figures and discrete pleomorphism. The presence of homogeneous hyaline material was observed with several foci of dystrophic calcification.

The biopsy of the lesion was performed and the microscopic sections showed polyhedral epithelial cell cords with eosinophilic cytoplasm, intercellular bridges, few mitotic figures and discrete pleomorphism. In the periphery of the lesion, there was presence of vacuolated cells with clear cytoplasm. From within the epithelial cell strands, there was a presence of hyaline material, homogeneous and with several foci of dystrophic calcification (Figure 2). In addition, neoplastic epithelial cells were negative. Through the association of clinical, imaging and histopathological aspects, the final diagnosis was Calcifying Epithelial Odontogenic Tumor (Tumor of Pindborg).

The clinical and radiographic characteristics of the lesion determined the marginal resection of the lesion, under general anesthesia, with local infiltration of $2 \%$ xylocaine and vasoconstrictor epinephrine at 1:200,000. An intra-oral incision was performed for exposure and resection of the lesion and preservation of the mandibular base allowing the maintenance of its shape. At the same surgical time, the extra-oral incision in the sub-mental region was chosen for adaptation of the reconstruction plate. Through osteotomies, $1 \mathrm{~cm}$ away from the tumor margins, the surgical specimen was resected and the 2.4 reconstruction plate was adapted (Figure 3(a) and Figure 3(b)).

After 1 year, local reconstruction with iliac bone graft was performed and fixed with 2.0 plates and screws (Figure 4(a)). About 1 month after the procedure, infection was observed in the grafted site, with exit of purulent secretion, requiring drainage and antibiotic therapy. After 6 months of reconstruction, bone graft fixation plates were removed and dental implant installation was performed (Figure 4(b)).

Due to the great manipulation of the soft tissues performed in the previous surgical procedures, a soft tissue defect was observed in the region and a epithelial and connective tissue graft removed from hard palate was done, with the 


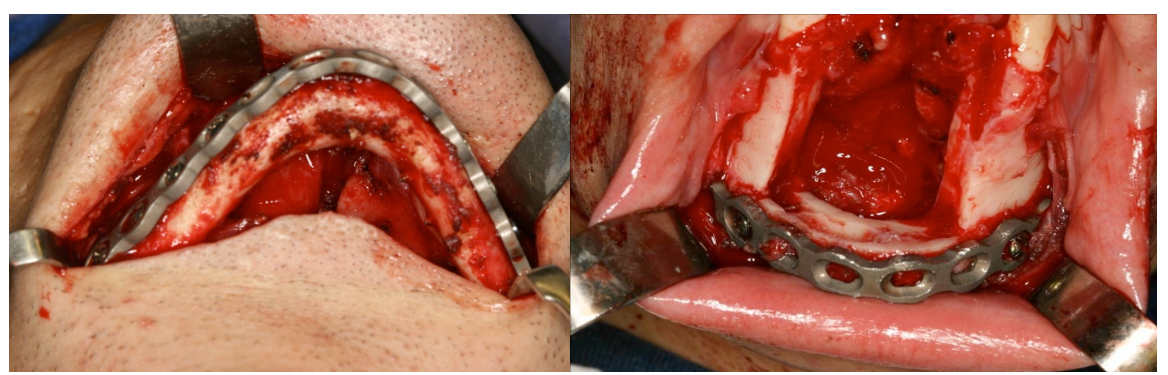

(a)

(b)

Figure 3. (a) Extra-oral incision and extensive jaw exposure; (b) Resected part with safety margin and margin of preserved mandible and reconstruction plate 2.4 adapted.

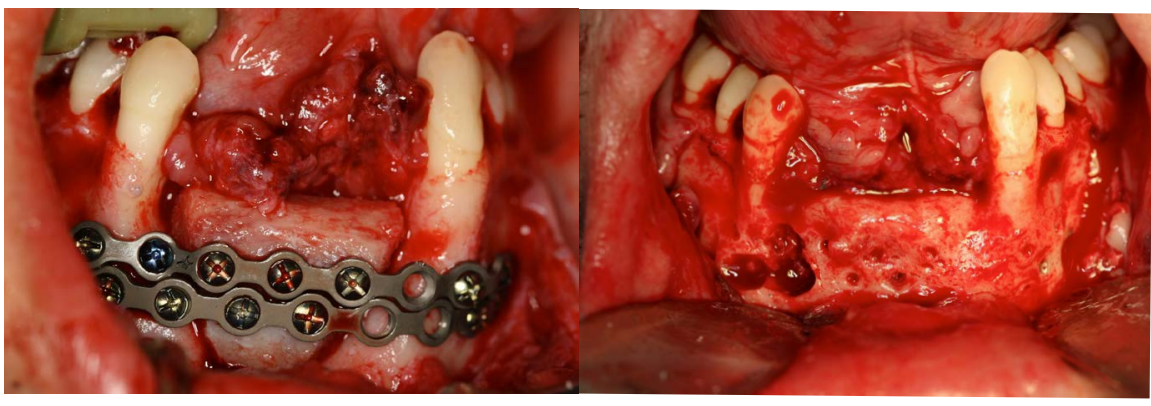

(a)

(b)

Figure 4. (a) Reconstruction of the previously resected area with iliac crest graft and fixation with plates and screws system 2.0; (b) Removal of fixation plates after 6 months of reconstruction before installation of dental implants.

objective of increasing the amount of keratinized mucosa and improve the peri-implant seal and consequently increase the success of the dental implants.

The bone graft and dental implants were good and without signs of tumor recurrence and a re-established masticatory function with definitive prostheses in the 8-year follow-up from the tumor removal (Figure 5).

\section{Discussion}

CEOT occurs most commonly in the posterior mandible region and is associated with retained teeth [3], however it can affect anterior region with or without association with retained teeth [2] as observed in the case reported.

Although CEOT is benign and has slow growth [1] it is a tumor with high growth potential and local tissue invasion which implies in increase of the recurrence rates [7] [10] especially related to more conservative treatments, such as curettage [11] [12].

The literature is controversial about to the best surgical management. Some authors reported that in lesions of great proportions and indefinite margins, resection is the best treatment [1] [8] [9] [13]. In cases of small proportions and defined margins, enucleation by curettage can be employed [14] [15]. In the present case, we choose to perform marginal resection of the mandible with a safety margin, because it was an extensive lesion with indefinite limits that was 


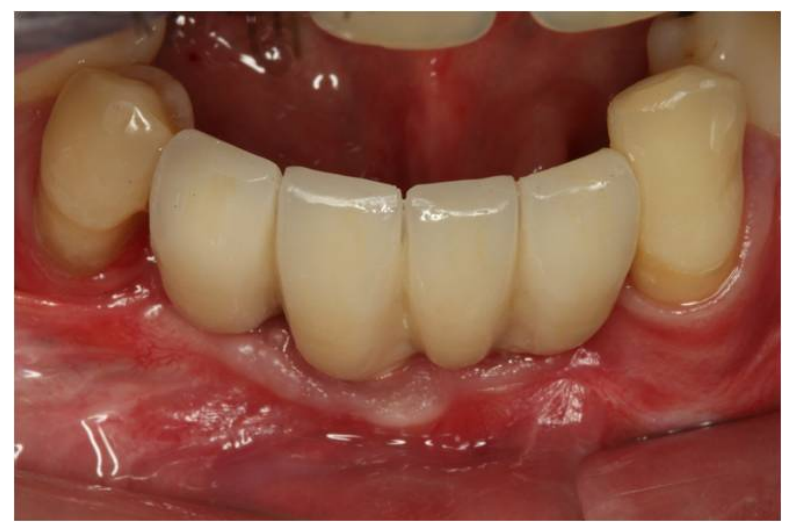

Figure 5. Final restoration with definitive prostheses.

involving soft tissue, bone and also teeth. Therefore, knowing that the tumor has high potential for growth and local tissue invasion, proceeding enucleation by curettage of the lesion alone would not be a resolutive treatment and probably it will be favourable to tumor recurrence.

The predominant factors in this case, in order to opt for marginal resection, were the multilocular aspect of the lesion, the absence of clearly defined borders and the involvement of teeth within the tumor mass. Obviously when we resected a bone or even part of it, especially when teeth are involved in the resection, it creates a new problem for the individual, which is the need to replace missing teeth. When there is intention to replace the lost teeth by means of supported implants, it is also necessary to reconstruct the hard and soft tissues aiming for the installation of dental implants and their longevity.

The main objective of all reconstruction is the restoration of form and function. The first involves preserving the patient's labial competence and maintaining favourable speech articulation, and the second is to return the best possible masticatory function to the patient, allowing him to have a relatively normal diet [16].

Many options are available for mandibular reconstruction, such as reconstruction plates isolated or associated with bone grafts, vascularized or not, or osteogenic distraction devices incorporated into the fixation system using remaining healthy bone [17].

Bone grafts allow the treatment of a series of alveolar bone defects, either in thickness or height defects [18]. An important determinant for bone graft predictability is the presence of autogenous bone as a component of the graft, since it has the property of bone formation from cells transplanted from the spongy bone, in addition, it contributes to the growth of the bone with various growth factors that are released during the incorporation of the graft, forming bone by means of induction [19].

Both vascularized and non-vascularized techniques are well accepted treatment strategies for mandibular reconstruction. For defects less than $6 \mathrm{~cm}$, especially in cases of benign conditions or due to some facial trauma, reconstruction with non-vascularized bone grafts should be considered, which allow a faster 
recovery and facilitate rehabilitation later with dental implants. In cases of primary reconstruction for segmental defects, patients with a history of radiotherapy, defects greater than $6 \mathrm{~cm}$, with need of composite hard/soft tissue, the vascularized bone graft is indicated [20].

The anterior and/or posterior iliac crest is a donor site commonly used in cases of non-vascularized techniques, highly successful in reconstructions of non-cancer patients [20] and dental implants should be installed after 4 to 6 months [19]. Regardless of the type of graft chosen for reconstruction it is important to put the implants as soon as possible to stimulate the formation and maintenance of the bone tissue [19].

In general, dental implants are good option for the rehabilitative treatment of total and partial edentulous patients [16] [17] and the success rate in this kind of case is about $96 \%$ [21] although the 10-year longitudinal study of Keller [22] evaluated 400 implants installed in the anterior region of the mandible after autogenous iliac crest bone grafting in $91.7 \%$ of cases.

Regardless of the area being grafted or not, in order to achieve success and greater predictability of treatment, factors such as quality and quantity of bone tissue, location of the implant, adequate initial stabilization of the dental implants, absence of habits, good general hygiene condition and the presence of soft tissue around the implant are fundamental to the aforementioned objectives (masticatory, phonetic and aesthetic function) were achieved [16] [17].

The relationship between the condition of the periodontal tissue and the bone tissue is directly related to the longevity of the dental implants [18] and the absence of keratinized mucosa on the reduced or thin border increases the chances of failure of the implants [18]. During planning it is important to determine if soft tissue augmentation therapy will be performed before, during or after implant placement [23]. In general, the optimal time for using peri-implant plastic techniques is preferably prior to or at the time of implant installation [23].

The sub-epithelial connective tissue graft is indicated to be performed when the absence of keratinized mucosa, loss of soft tissue thickness, exposure of the prosthetic component and papilla alteration exist [23]. This graft, when well performed and indicated, has the capacity to increase the metabolic activity at the receptor site, increasing and preserving the amount of keratinized mucosa, since it induces the keratinization of the epithelial cells that will proliferate on the graft, obtaining, in this way, a better peri-implant marginal seal [17].

Among the many difficulties encountered in reconstruction cases, post-resection and post-graft soft tissue characteristics are prominent. In the case in question, soft tissue was lost during tumor resection, with the result that, after bone reconstruction with an iliac crest graft, soft tissue was deficient. In addition, the correct adaptation and prognosis of soft tissues is quite unpredictable, and in many cases there is a need for the association of local grafts for the future prosthesis present better conditions [16] [19], which was performed in this case. We choose to use a sub-epithelial connective tissue graft of the hard palate, aiming to increase the amount of keratinized mucosa around the implants, thus obtain- 
ing better peri-implant marginal sealing, consequently increasing the chances of success of the implants installed.

Factors such as unsatisfactory soft tissue closure, contamination of grafts by endogenous bacteria, or failure of aseptic surgical technique may lead to the loss of any graft performed [18]. When there is exposure of the fixation material, an invasion of bacteria occurs to the grafted region, generating local inflammation and decreased bone formation [24]. Therefore, the primary closure of the soft tissue is determinant for the success of the graft, ensuring healing by first intention in addition to reduce the patient's postoperative discomfort [19].

In case of contamination, the treatment of this type of complication depends mainly on the presence of local exudate or not. When the infection is small, with only local erythema, one should proceed with physical debridement, through irrigation with $0.12 \%$ chlorhexidine or physiological solution. In cases with purulent secretion, in addition to the local debridement, the use of antimicrobials should be associated [18]. In the reported case, the iliac crest bone graft was successful despite a postoperative infection, which required local drainage, irrigation with saline solution and rigorous patient follow-up plus antimicrobial prescription.

Following all the steps for prosthetic rehabilitation (bone reconstruction, soft tissue reconstruction, installation of dental implants) it is essential to periodically follow these patients. Despite the possibility of relapse being reduced in cases where mandibular resection was performed, it is not ruled out. In the case reported, the patient presented a postoperative period of 8 years after the tumor removal and good prognosis. In addition, because it is an implant-supported rehabilitation, there is a need for periodontal, occlusal and stability of the implants, always seeking the motivation of the patient to perform adequate oral hygiene.

\section{Conclusion}

Knowing the aggressive behavior of CEOT and its potential for relapse, surgical excision should be considered. However, when opted for this treatment, planning for bone reconstruction and restoration of the normal anatomy, function and aesthetics it is important to keep in mind the necessities for rehab the patient and be able to treat possible complications that may arise during all procedures.

\section{Consent}

The patient had given his consent for this case report to be published. This Statement is in the cover of the chart at the Bauru School of Dentistry.

\section{Conflicts of Interest}

The authors declare no conflicts of interest regarding the publication of this paper.

\section{References}

[1] Chrcanovic, B.R. and Gomez, R.S. (2017) Calcifying Epithelial Odontogenic Tumor: 
An Updated Analysis of 339 Cases Reported in the Literature. Journal of Cranio-Maxillo-Facial Surgery, 45, 1117-1123. https://doi.org/10.1016/j.jcms.2017.05.007

[2] Shetty, S.J., Pereira, T. and Desai, R.S. (2016) Peripheral Clear Cell Variant of Calcifying Epithelial Odontogenic Tumor: Case Report and Review of the Literature. Head and Neck Pathology, 10, 481-485. https://doi.org/10.1007/s12105-016-0726-5

[3] Souza, B.L.M., Nascimento, D.F., Sampaio, D.O., Farias, I.P.S., Nogueira, E.F.C. and Torres, B.C.A. (2015) Mandibular Resection and Immediate Reconstruction for Pindborg Tumor Treatment. Brazilian Journal of Surgery and Clinical Research, 9, 32-35.

[4] Abrams, A.M. and Howell, F.V. (1967) Calcifying Epithelial Odontogenic Tumors: Report of Four Cases. The Journal of the American Dental Association, 74, 1231-1240. https://doi.org/10.14219/jada.archive.1967.0426

[5] Hicks, M.J., Flaitz, C.M., Wong, M.E., et al. (1994) Clear Cell Variant of Calcifying Epithelial Odontogenic Tumor: Case Report and Review of the Literature. Head \& Neck, 16, 272-277. https://doi.org/10.1002/hed.2880160311

[6] Abrahão, A.C., Camisasca, D.R., Bonelli, B.R.M.V., Cabral, M.G., Lourenço, S.Q.C., Torres, S.R. and Pinto, J.R. (2009) Recurrent Bilateral Gingival Peripheral Calcifying Epithelial Odontogenic Tumor (Pindborg Tumor): A Case Report. Oral Surgery, Oral Medicine, Oral Pathology, Oral Radiology, and Endodontology, 108, 66-71. https://doi.org/10.1016/j.tripleo.2009.04.037

[7] Rydin, K., Sjöström, M. and Warfvinge, G. (2016) Clear Cell Variant of Intraosseous Calcifying Epithelial Odontogenic Tumor: A Case Report and Review of the Literature. Oral and Maxillofacial Pathology, 122, e125-e130.

https://doi.org/10.1016/j.oooo.2016.01.001

[8] Serrilho, R.P., Tolentino, L.S. and Pinto, G.N.S. (2015) Soft Tissue Grafting as an Option to Address Peri-Implant Defects. Clinical Case Report. Revista da Associação Paulista de Cirurgióes Dentistas, 69, 350-354.

[9] Afrogheh, A., Schneider, J., Mohamed, N. and Hille, J. (2014) Calcifying Epithelial Odontogenic Tumor with Clear Langerhans Cells: A Novel Variant, Report of a Case and Review of the Literature. Head and Neck Pathology, 8, 214-219. https://doi.org/10.1007/s12105-013-0490-8

[10] Ai-Ru, L., Zhen, L. and Jian, S. (1982) Calcifying Epithelial Odontogenic Tumors: A Clinicopathologic Study of Nine Cases. Journal of Oral Pathology \& Medicine, 11, 399-406. https://doi.org/10.1111/j.1600-0714.1982.tb00181.x

[11] Cheng, Y.S.L., Wright, J.M., Walstad, W.R. and Finn, M.D. (2002) Calcifying Epithelial Odontogenic Tumor Showing Microscopic Features of Potentially Malignant Behavior. Oral Surgery, Oral Medicine, Oral Pathology, Oral Radiology, and Endodontology, 93, 287-295. https://doi.org/10.1067/moe.2002.121991

[12] Oliveira, M.G., Chaves, A.C.M., Visioli, F., Rojas, E.U., Moure, S.P., Romanini, J., Mariath, J.E.A., Rados, P.V. and Filho, M.S. (2009) Peripheral Clear Cell Variant of Calcifying Epithelial Odontogenic Tumor Affecting 2 Sites: Report of a Case. Oral Surgery, Oral Medicine, Oral Pathology, Oral Radiology, and Endodontology, 107, 407-411. https://doi.org/10.1016/j.tripleo.2008.11.004

[13] Rani, V., Masthan, M.K., Aravindha, B. and Leena, S. (2016) Aggressive Calcifying Epithelial Odontogenic Tumor of the Maxillary Sinus with Extraosseous Oral Mucosal Involvement: A Case Report. Iranian Journal of Medical Sciences, 41, 145-149.

[14] Yaedú, R.Y.F., Rocha, J.F., Dias-Ribeiro, E., Consolaro, A., Lara, V.S. and Sant'ana, 
E. (2013) Tratamiento conservador de tumor epitelial odontogénico calcificante asociado al canino inferior retenido: Relato de caso clínico. Revista Española de Cirugía Oral y Maxilofacial, 35, 123-127.

https://doi.org/10.1016/j.maxilo.2011.09.007

[15] Munteanu, C., Pirici, D., Stepan, A.E., Camen, A. and Margaritescu, C. (2016) Maxillary Calcifying Epithelial Odontogenic Tumor with Sinus and Buccal Vestibule Extension: A Case Report and Immunohistochemical Study. Diagnostic Pathology, 11, Article No. 134. https://doi.org/10.1186/s13000-016-0582-3

[16] Baker, A., Macmabon, J. and Parmar, S. (2001) Immediate Reconstruction of Continuity Defects of the Mandible after Tumor Surgery. Journal of Oral and Maxillofacial Surgery, 59, 1333-1339. https://doi.org/10.1053/joms.2001.27825

[17] Goh, B.T., Lee, S., Tideman, H. and Stoelinga, P.J. (2008) Mandibular Reconstruction in Adults: A Review. International Journal of Oral and Maxillofacial Surgery, 37, 597-605. https://doi.org/10.1016/j.ijom.2008.03.002

[18] Mazonetto, R. (2009) Reconstruções em implantodontia: Protocolos clínicos para o sucesso e previsibilidade. Napoleão, Nova Odessa, 268.

[19] Misch, C.E. (2005) Dental Implant Prosthetics. Mosby, St Louis.

[20] Osborna, T.M., Helalb, D. and Mehraa, P. (2018) Iliac Crest Bone Grafting for Mandibular Reconstruction: 10-Year Experience Outcomes. Journal of Oral Biology and Craniofacial Research, 8, 25-29. https://doi.org/10.1016/j.jobcr.2017.12.001

[21] Tolman, T.E. (1995) Reconstructive Procedures with Endosseous Implants in Grafted Bone: A Review of the Literature. The International Journal of Oral \& Maxillofacial Implants, 10, 275.

[22] Keller, E.E. (1995) Reconstruction of the Severely Atrophic Edentulous Mandible with Endosseous Implants: A 10-Year Longitudinal Study. Journal of Oral and Maxillofacial Surgery, 53, 305-320. https://doi.org/10.1016/0278-2391(95)90231-7

[23] Pinto, F.R., Menezes, K.M., Fernandes, A.N., Moranza, T.A., Ciotti, D.L. and Gurgel, B.C.V. (2014) Connective Tissue Graft in Patient with Dental Implants in the Anterior Region Case Report. Revista da Associação Paulista de Cirurgióes Dentistas, 68, 106-111.

[24] Berglundh, T., Persson, L. and Klinge, B. (2002) A Systematic Review of the Incidence of Biological and Technical Complications in Implant Dentistry Reported in Prospective Longitudinal Studies of at Least 5 Years. Journal of Clinical Periodontology, 29, 197-212. https://doi.org/10.1034/j.1600-051X.29.s3.12.x 